Please cite as:

Dolnicar, S. (2020). Eat up! Prevention of plate waste in tourism and hospitality: a perspective paper. Tourism Review.

DOI 10.1108/TR-05-2019-0199

\title{
Eat Up! Prevention of Plate Waste in Tourism and Hospitality A Perspective Paper
}

\author{
Sara Dolnicar \\ Tourism | UQ Business School | The University of Queensland | Australia
}

\section{Introduction}

The tourism industry is critical to economies globally. It also burdens the environment, contributing $8 \%$ of total greenhouse emissions (Lenzen et al., 2018), and generating 35 million tons of solid waste annually (UNEP \& WTO, 2012), including in pristine natural areas (e.g. Kaseva \& Moirana, 2010). As the tourism industry continues to grow (World Bank, 2019), so does its negative environmental impact. New approaches to making tourism more environmentally sustainable are urgently needed. One such approach is preventing plate waste. Plate waste is edible food served on a plate, but not eaten. As opposed to kitchen food waste, $92 \%$ of plate waste is avoidable (Papargyropoulou et al., 2016). This perspective article synthesizes past research on plate waste, and outlines a future research agenda.

\section{Past perspective 75 years of developments 1946-2020}

While tourism research has a proud history of nearly a century, environmentally sustainable tourism has only been investigated for three decades (Bramwell \& Lane, 1993). Early work focused on quantifying the environmental cost of tourism. Food waste emerged as highly harmful (Gössling et al., 2011) yet underresearched (Gössling \& Peeters, 2015; Papargyropoulou et al., 2016).

Food production drives climate change because it is highly resource intensive (Foley et al., 2011). Uneaten food wastes the resources needed for production, transport, storage and preparation, and - in landfill - produces methane, which "warms the planet by 86 times as much as CO2" (Vaidyanathan, 2015). Daily plate waste per hotel guest amounts to $15 \mathrm{~g}$ at breakfast buffets (Juvan, Grün \& Dolnicar, 2018), and to 233g across all meals of the day (Papargyropoulou et al., 2016).

Although waste prevention is firmly on the agenda of some European countries, most efforts are directed towards waste management after waste has been generated (Pirani \& Arafat, 2014; Sealey \& Smith, 2014). Waste prevention is preferable; it avoids the need for waste disposal, and saves all resources needed for production. Preventing plate waste in tourism implies changing the behaviour of paying customers. Only few academic studies have offered scientifically proven viable solutions: reducing plates by three centimetres prevents $20 \%$ of plate waste (Kallbekken \& Sælen, 2013); inviting guests to return to the buffet as often as they want prevents $21 \%$ (Kallbekken \& Sælen, 2013); and rewarding families with stamps and prizes reduces plate waste in this segment - known to leave behind most uneaten food (Juvan, Grün \& Dolnicar, 2018) - by 34\% (Dolnicar, Juvan \& Grün, 2019).

Other effective measures include charging a fine for plate waste (e.g. Kuo \& Shih, 2016), not providing trays (e.g. Kim \& Freedman, 2010), and reducing portion sizes (e.g. Freedman \& Brochado, 2010), but these measures are of limited value to hotels and restaurants. Figure 1 provides an overview of approaches to reducing plate waste, using as axes: (1) suitability for the hospitality sector and (2) whether or not measures have been scientifically proven to be effective. For any measure to be suitable in the tourism and hospitality sector, it cannot imply a punishment for unwanted behaviours, and cannot reduce guest satisfaction. As a 
consequence, some of the interventions proven to be effective in other contexts - such as being charged a fine for leftovers on the plate - cannot be used in tourism and hospitality. The x-axis in Figure 1 distinguishes between measures that have been suggested to work (typically by industry associations), but never empirically proven to be effective, and those that have been put to a scientific test, optimally by investigating the effect on actual tourist behaviour experimentally in the real world hotel or restaurant context.

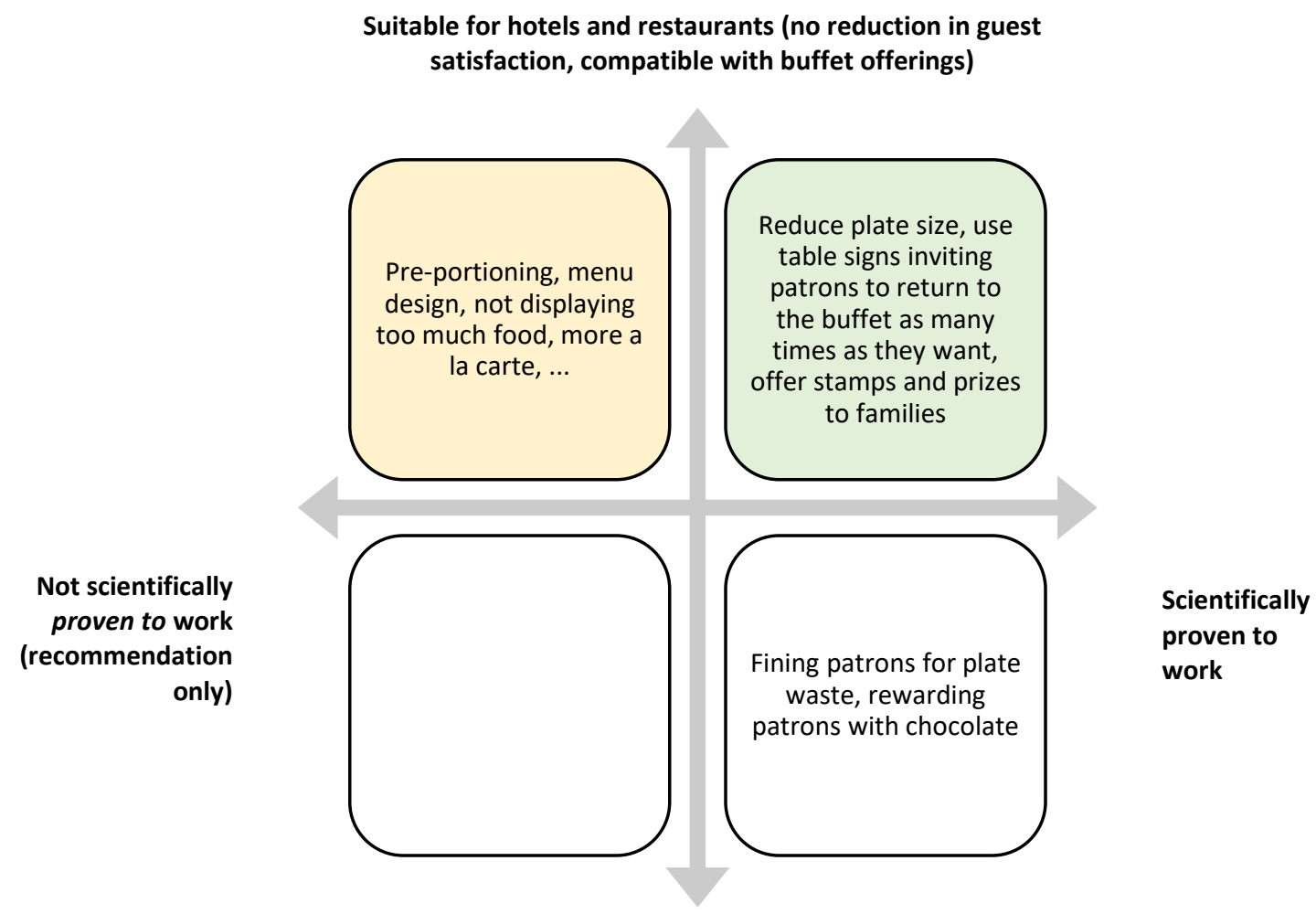

Not suitable for hotels and restaurants (reduction in guest satisfaction or incentive not effective given offerings at the buffet)

Figure 1. A systematics of approaches to reducing plate waste

The measures in the top right quadrant are available for immediate uptake by industry. This quadrant also represents the area towards which future research attention needs to be directed.

\section{Future perspective 75 years 2020-2095}

With the world's population continuing to grow and the burden of agriculture and food disposal on the environment increasing, the prevention of all types of waste - including plate waste - will become an even more pressing issue in future. While technology can assist in preventing some kinds of food waste, especially edible food leftovers, it has little potential to solve the plate waste challenge because plate waste is contaminated and by law has to be discarded in many jurisdictions when generated in the commercial hospitality sector. As a consequence, future research must focus on prevention. This can be achieved by pursuing the following three research streams:

Theory on plate waste generation. To date, only few attempts have been made to explain plate waste generation (Dolnicar \& Juvan, 2019), identifying key drivers, including food quality, portioning, lack of food expertise, unfamiliar foods, unconscious overserving, lack of control, and laziness. More theoretical work is needed to inform theory-guided practical measures.

Development and experimental testing of theory-guided measures. Experiments using actual plate waste as a dependent variable are needed to draw reliable causal conclusions about the effectiveness of such measures. Figure 1 shows this type of work in the green (top right) quadrant. 
Experimental testing of industry-driven measures. Industry associations offer practical tips, including: serving a la carte; designing menus in line with guest preferences; not displaying too much food, and preportioning (PATA, 2018). Some tourism businesses develop their own approaches. P\&O cruises, for example, offer no buffets. Instead, chefs serve freshly made food in set portion sizes. The Pantry - as P\&O Cruises call their concept - maintains the informal character of the dining experience, while reflecting a world-wide cultural shift toward waste prevention (Karlsson, 2019). The relative effectiveness of such applied solutions must be assessed experimentally in future. Figure 1 shows this type of work in the yellow (top left) quadrant.

\section{Conclusions}

At first glance, the issue of plate waste appears to be minor. It is not: with 11-13 percent of food served to people not eaten, plate waste represents a major global challenge. Despite the increasing attention paid to waste prevention by national and international environmental agencies, surprisingly little effort has been directed towards reducing plate waste. Only a limited number of scientifically proven measures exist to assist accommodation providers and restaurants in preventing the amount of plate waste generated. More such measures need to be developed, experimentally tested, and widely disseminated to maximize uptake and, with it, minimize the unnecessary environmental burden caused by food taken by patrons, but ultimately discarded.

\section{References}

Dolnicar, S. \& Juvan, E. (2019) Drivers of plate waste: A mini theory of action based on staff observations. Annals of Tourism Research, https://doi.org/10.1016/j.annals.2019.05.008.

Dolnicar, S., Juvan, E. \& Grün, B. (2019) Reducing the plate waste of families at hotel buffets. Manuscript under review, paper presented at the Biannual Conference of the International Academy for the Study of Tourism, 6-11 May 2019, Bali, Indonesia.

Foley, J.A. et al. (2011). Solutions for a cultivated planet. Nature, 478(7369), 337-342.

Freedman, M.R. \& Brochado, C. (2010) Reducing portion size reduces food intake and plate waste. Obesity, 18(9), 1864-1866.

Gössling, S. \& Peeters, P. (2015) Assessing tourism's global environmental impact 1900-2050. Journal of Sustainable Tourism, 23(5), 639-659.

Gössling, S., Garrod, B., Aall, C., Hille, J. \& Peeters, P. (2011) Food management in tourism: Reducing tourism's carbon 'foodprint'. Tourism Management, 32(3), 534-543.

Juvan, E., Grün, B. \& Dolnicar, S. (2018) Biting off more than they can chew: food waste at hotel breakfast buffets. Journal of Travel Research, 57(2), $232-242$.

Kallbekken, S. \& Sælen, H. (2013) 'Nudging' hotel guests to reduce food waste as a win-win environmental measure. Economics Letters, 119(3), 325-327.

Karlsson, T. (2019) Personal communication with the Vice-President of Guest Experience, Thomas Karlsson, P\&O Cruises, 29.3.2019.

Kaseva, M.E. \& Moirana, J.L. (2010) Problems of solid waste management on Mount Kilimanjaro: A challenge to tourism. Waste Management \& Research, 28(8), 695-704.

Kim, T. \& Freedman, M.R. (2010) Students reduce plate waste through education and trayless dining in an all-you-can-eat college dining facility. Journal of the American Dietetic Association, 110(9), doi:10.1016/j.jada.2010.06.253

Kuo, C. \& Shih, Y. (2016) Gender differences in the effects of education and coercion on reducing buffet plate waste. Journal of Foodservice Business Research, 19(3), 223-235.

Lenzen, M., Sun, Y.Y., Faturay, F., Ting, Y.P., Geschke, A. \& Malik, A. (2018) The carbon footprint of global tourism. Nature Climate Change, 8(6), 522-527.

Papargyropoulou, E., Wright, N., Lozano, R., Steinberger, J., Padfield, R. \& Ujang, Z. (2016) Conceptual framework for the study of food waste generation and prevention in the hospitality sector. Waste Management, 49, 326-336.

PATA (2018) Buffet toolkit - Building and understanding for food excess in tourism. Bangkok: Pacific Asia Travel Association (PATA).

Pirani, S.I. \& Arafat, H.A. (2014) Solid waste management in the hospitality industry: A review. Journal of Environmental Management, 146, 320-336.

Sealey, K.S. \& Smith, J. (2014). Recycling for small island tourism developments: Food waste composting at Sandals Emerald Bay, Exuma, Bahamas. Resources, Conservation and Recycling, 92, 25-37.

Shanklin, C.W., Petrillose, M.J. \& Pettay, A. (1991) Solid waste management practices in selected hotel chains and individual properties. Hospitality Research Journal, 15(1), 59-74.

UNEP \& WTO (2012) Tourism in the green economy - background report. Madrid: UNWTO.

Vaidyanathan, G. (2015) How bad of a greenhouse gas is methane? Scientific American, 22.

World Bank (2019) International tourism, number of arrivals, https://data.worldbank.org/indicator/ST.INT.ARVL, accessed 20.8.2019. 